\title{
Optical suppression of drug-evoked phasic dopamine release
}

\section{James E. McCutcheon ${ }^{1}{ }^{+}$, Jackson J. Cone ${ }^{1}$, Christopher G. Sinon ${ }^{1}$, Samantha M. Fortin ${ }^{1}$, Pranish A. Kantak ${ }^{2}$, Ilana B. Witten ${ }^{3}$, Karl Deisseroth ${ }^{4}$, Garret D. Stuber ${ }^{2}$ and Mitchell F. Roitman ${ }^{1 *}$}

${ }^{1}$ Department of Psychology, University of Illinois at Chicago, Chicago, IL, USA

${ }^{2}$ Department of Psychiatry and Department of Cell Biology and Physiology, University of North Carolina, Chapel Hill, NC, USA

${ }^{3}$ Princeton Neuroscience Institute and Department of Psychology, Princeton University, Princeton, NJ, USA

${ }^{4}$ Departments of Bioengineering, Psychiatry and Behavioral Sciences, Howard Hughes Medical Institute, and CNC Program, Stanford University, Stanford, CA, USA

\section{Edited by:}

Herwig Baier, Max Planck Institute of Neurobiology, Germany

\section{Reviewed by:}

Kuan H. Wang, National Institute of

Mental Health, USA

Ralph DiLeone, Yale University

School of Medicine, USA

${ }^{*}$ Correspondence:

James E. McCutcheon, Department

of Cell Physiology and

Pharmacology, University of Leicester, Medical Sciences

Building, University Road, Leicester, LE1 9HN, UK

e-mail: jem64@le.ac.uk;

Mitchell F. Roitman, Department of

Psychology, University of Illinois at

Chicago, Behavioral Sciences

Building, 1007 W Harrison Street,

Chicago, IL 60607, USA

e-mail:mroitman@uic.edu

${ }^{\dagger}$ Present address:

Department of Cell Physiology and

Pharmacology, University of

Leicester, Leicester, UK
Brief fluctuations in dopamine concentration (dopamine transients) play a key role in behavior towards rewards, including drugs of abuse. Drug-evoked dopamine transients may result from actions at both dopamine cell bodies and dopamine terminals. Inhibitory opsins can be targeted to dopamine neurons permitting their firing activity to be suppressed. However, as dopamine transients can become uncoupled from firing, it is unknown whether optogenetic hyperpolarization at the level of the soma is able to suppress dopamine transients. Here, we used in vivo fast-scan cyclic voltammetry to record transients evoked by cocaine and raclopride in nucleus accumbens (NAc) of urethane-anesthetized rats. We targeted halorhodopsin ( $\mathrm{NpHR}$ ) specifically to dopamine cells by injecting Cre-inducible virus into ventral tegmental area (VTA) of transgenic rats that expressed Cre recombinase under control of the tyrosine hydroxylase promoter $\left(\mathrm{TH}-\mathrm{Cre}{ }^{+}\right.$ rats). Consistent with previous work, co-administration of cocaine and raclopride led to the generation of dopamine transients in NAc shell. Illumination of VTA with laser strongly suppressed the frequency of transients in NpHR-expressing rats, but not in control rats. Laser did not have any effect on amplitude of transients. Thus, optogenetics can effectively reduce the occurrence of drug-evoked transients and is therefore a suitable approach for studying the functional role of such transients in drug-associated behavior.

Keywords: fast-scan cyclic voltammetry, nucleus accumbens, optogenetics, dopamine transients, TH-Cre, rat

\section{INTRODUCTION}

Generation of burst firing in dopamine neurons is a common feature of all abused drugs (Gysling and Wang, 1983; Mereu et al., 1987; Gessa et al., 1998; Brodie et al., 1999; Koulchitsky et al., 2012). Burst firing results in phasic increases in dopamine in terminal regions, known as dopamine concentration "transients" (Sombers et al., 2009; Owesson-White et al., 2012), which are necessary and sufficient for positive reinforcement and associative learning (Tsai et al., 2009; Steinberg et al., 2013). Transients occur both spontaneously and in response to rewarding or salient environmental stimuli (Day et al., 2007). In addition, they are dramatically enhanced in frequency and amplitude by many abused drugs including ethanol, cocaine, nicotine, and cannabinoids (Cheer et al., 2004, 2007; Aragona et al., 2008; Robinson et al., 2009). Indeed, generation of de novo dopamine transients, rather than simply augmenting ongoing ones, seems to be a key feature of all abused drugs (Covey et al., 2014). Thus burst firing and the dopamine concentration transients it produces are likely to play a key role in the development and maintenance of drug-seeking behaviors.

Optogenetics provides a method for determining the role of dopamine transients in positive reinforcement, associative learning and goal directed behaviors including behaviors directed at drugs of abuse. Indeed, mice prefer locations that have been previously paired with phasic, selective activation of dopamine neurons (Tsai et al., 2009). Moreover, rats will self-administer laser pulses that depolarize dopamine cell bodies or dopamine terminals and thus evoke phasic increases in nucleus accumbens (NAc) dopamine (Witten et al., 2011; Steinberg et al., 2014). In stark contrast, locations paired with selective inhibition of dopamine neurons by activation of inhibitory opsins are avoided (Tan et al., 2012; Tye et al., 2013; Danjo et al., 2014). Recently, inhibitory opsins have been used to suppress NAc dopamine release evoked by electrical stimulation of dopamine cell bodies as well as basal levels of NAc dopamine (Danjo et al., 2014). However, the degree to which cell body inhibition via optogenetics affects drug-induced dopamine signaling 
remains unknown. This is a critical gap in knowledge especially in light of drug effects directly on dopamine terminals (Lüscher and Ungless, 2006) as well as mechanisms at dopamine terminals that can drive release in a cell body independent manner (Exley and Cragg, 2008; Cachope et al., 2012; Threlfell et al., 2012).

Drug-evoked dopamine transients may drive drug-seeking behavior in several ways and transients are known to correlate with operant behaviors to obtain drug (Phillips et al., 2003; Willuhn et al., 2012). However, to date, no studies have assessed the ability of optogenetics to suppress drug-induced, dopamine concentration transients. Here, we use fast-scan cyclic voltammetry to record drug-evoked dopamine concentration transients in NAc while we hyperpolarized the soma of dopamine neurons expressing the inhibitory opsin, halorhodopsin (NpHR). We show that brief somatic hyperpolarization is sufficient to robustly suppress NAc dopamine concentration transients evoked by drugs.

\section{MATERIALS AND METHODS SUBJECTS}

Transgenic rats (Long-Evans background) expressing Cre recombinase under the control of the tyrosine hydroxylase promoter ( $\mathrm{TH}-\mathrm{Cre}^{+}$rats; Witten et al., 2011) and wild-type litter mates ( $\mathrm{TH}-\mathrm{Cre}^{-}$rats) were bred from female $\mathrm{TH}-\mathrm{Cre}^{+}$and male wildtype Long-Evans rats (Charles River). All rats used were male and weighed 275-350 g at time of initial surgery. Rats were grouphoused until surgery and singly housed thereafter. Standard housing conditions were provided (temperature, $22^{\circ} \mathrm{C}$; humidity, $30 \% ; 12: 12$ h light:dark cycle, lights on at 07:00 h) with ad libitum access to food and water. Animal care and use was in accordance with the National Institutes for Health Guide for the Care and Use of Laboratory Animals, and approved by the Institutional Animal Care and Use Committee at the University of Illinois at Chicago.

\section{VIRAL INFECTION}

The following Cre-dependent viruses (titer, 1.5-4 × $10^{12}$ particles/mL; serotype AAV5) were purchased from University of North Carolina Vector Core: AAV-EF1a-DIO-eNpHR3.0-EYFP (NpHR); AAV-EF1a-DIO-EYFP (eYFP). TH-Cre ${ }^{+}$rats infused with NpHR ( $N p H R$-expressing rats; $n=8$ ) were compared to $\mathrm{TH}$ $\mathrm{Cre}^{+}$rats infused with eYFP or TH-Cre ${ }^{-}$rats infused with NpHR (control rats; $n=5$ ).

Rats were anesthetized with ketamine hydrochloride (100 mg/kg, i.p.) and xylazine hydrochloride $(10 \mathrm{mg} / \mathrm{kg}$, i.p.), and $2 \mu \mathrm{L}$ of appropriate virus (see above) was infused using a custom made injector with tips separated $0.8 \mathrm{~mm} \mathrm{AP}$ and $1 \mathrm{~mm}$ DV (adapted from Witten et al., 2011); this permitted two simultaneous infusions at different depths to be made. Coordinates to target the ventral tegmental area (VTA) were as follows (in $\mathrm{mm}$ ): -5.4 and $-6.2 \mathrm{AP},+0.7 \mathrm{ML}$ from Bregma and -8.4 and $-7.4 \mathrm{DV}$ from skull surface. $1 \mu \mathrm{L}$ of virus was infused at each location at a rate of $0.1 \mu \mathrm{L} / \mathrm{min}$. The infuser was left in place for an additional 8-10 min before being removed. All infusions were made unilaterally. Rats were left in home cage for 6-10 weeks before voltammetry experiments took place.

\section{FAST-SCAN CYCLIC VOLTAMMETRY AND OPTOGENETIC SUPPRESSION}

Procedures for recording dopamine release using voltammetry were similar as described previously (Cone et al., 2013). Rats were anesthetized with urethane $(1.5-2.0 \mathrm{~g} / \mathrm{kg}$, i.p.) and mounted in a stereotaxic instrument. A guide cannula was directed towards the NAc shell ( $\mathrm{mm}$ from Bregma: +1.7 AP; +0.9 ML) ipsilateral to the viral infusion and a $\mathrm{Ag} / \mathrm{AgCl}$ reference electrode was placed in contralateral cortex; these were fixed to the skull using screws and dental cement. An optical fiber (Thor Labs; $200 \mu \mathrm{m}, 0.37$ numerical aperture, Sparta et al., 2012) was positioned dorsal to VTA (in mm: -5.8 from Bregma; -7.5 to -8.0 from skull surface). A glass-insulated carbon-fiber electrode was lowered into NAc shell using a custom made micromanipulator (UIC Biologic Resources Center). Dopamine concentration transients were evoked by systemic administration (i.p.) of cocaine $(10 \mathrm{mg} / \mathrm{kg})$ and raclopride $(1 \mathrm{mg} / \mathrm{kg})$, which resulted in production of dopamine transients as previously shown (Venton and Wightman, 2007; Aragona et al., 2008; Park et al., 2010). After establishment of dopamine release, a DPSS laser light source (532 nm; 10-15 mW) was used to illuminate the VTA via the optic fiber for discrete $5 \mathrm{~s}$ epochs. Laser power was calibrated before and after every experiment using a power meter (PM100USB; Thorlabs). Voltammetry data were continuously collected in serial $15 \mathrm{~s}$ files with the laser turned on for $5 \mathrm{~s}$ in every other file. For each rat, 10 "laser on" trials were compared with 10 "laser off" trials.

\section{DRUGS}

Cocaine hydrochloride (UIC Pharmacy) and S(-)-raclopride (+)-tartrate salt (Sigma-Aldrich) were dissolved in sterile saline at $10 \mathrm{mg} / \mathrm{mL}$ and $1 \mathrm{mg} / \mathrm{mL}$, respectively, before injecting.

\section{HISTOLOGY}

At the end of recording rats were transcardially perfused. Brains were removed and post-fixed in formalin for $24 \mathrm{~h}$ followed by $30 \%$ sucrose in $0.1 \mathrm{M}$ phosphate buffer $(\mathrm{PB})$. In a subset of rats, to double-label neurons, anti- $\mathrm{TH}$ immunohistochemistry was performed as previously described (McCutcheon et al., 2012). Briefly, $40 \mu \mathrm{m}$ sections were incubated with anti-TH primary antibody (Millipore, ab152; 1:500) for $72 \mathrm{~h}$ at $4^{\circ} \mathrm{C}$ and with goat anti-rabbit AlexaFluor 594 secondary antibody (Invitrogen, A11037, 1:250) for $90 \mathrm{~min}$ at room temperature before being cover-slipped. Images were collected on an Olympus FV1000 microscope.

\section{DATA ANALYSIS}

Dopamine concentration was extracted from current-voltage plots using principal component analysis (PCA), as previously described (Heien et al., 2004; Keithley et al., 2010). Electrodes were calibrated post-experiment in a custom built flow cell (Sinkala et al., 2012). The mean calibration factor was $54.77 \mathrm{nM} / \mathrm{nA}$.

Dopamine concentration transients were defined as brief elevations in dopamine concentration with fast rise time and decay kinetics similar to those seen after stimulating dopamine cell bodies. Mini Analysis v.6 (Synaptosoft) was used to objectively identify and analyze transients from concentration $x$ time traces. 
The epoch used for analysis began $1 \mathrm{~s}$ after the laser was turned on and ended when the laser was turned off. This was compared to an equivalent epoch in trials when the laser was never turned on. Paired $t$-tests were used to compare "laser on" trials to "laser off” trials. MATLAB was used to conduct statistical testing.

\section{RESULTS \\ EXPRESSION OF Cre-DEPENDENT VIRUS IN NAC-PROJECTING DOPAMINE NEURONS}

Infection of $\mathrm{TH}_{-} \mathrm{Cre}^{+}$rats with Cre-dependent virus led to expression of transgenes in midbrain dopamine neurons. Expression of eYFP reporter was seen throughout the VTA and substantia nigra compacta of $\mathrm{TH}-\mathrm{Cre}^{+}$rats (Figures 1, 2), but not in $\mathrm{TH}^{-\mathrm{Cre}^{-}}$rats (data not shown), as expected. Colocalization of eYFP with TH immunoreactivity was observed in the VTA of TH$\mathrm{Cre}^{+}$rats infected with Cre-dependent eYFP (Figure 1) demonstrating specificity of the transgenic strategy. eYFP intensity was greatest ipsilateral to the viral infusion although, in most animals, some expression was also observed contralaterally. Examination of terminal regions showed that transgene expression was present in neurons projecting to NAc, the site in which voltammetry recordings were made (Figure 2 ).

\section{COCAINE AND RACLOPRIDE ADMINISTRATION EVOKES DOPAMINE CONCENTRATION TRANSIENTS IN NAC}

Consistent with previous findings (Venton and Wightman, 2007), before drug administration, spontaneous dopamine transients were rarely observed; pre-drug transients were detected in 1 out of 13 rats and in this single rat transient frequency was 1.67 transients/min and mean amplitude was $12.96 \pm 0.40 \mathrm{nM}$. Coadministration of cocaine and raclopride led to generation of spontaneous, high amplitude transients in 11 out of 13 rats. In these 11 rats, mean transient frequency after drug was $10.31 \pm$ 1.63 transients/min and mean amplitude was $31.93 \pm 3.91 \mathrm{nM}$. Transients began approximately $10 \mathrm{~min}$ after drug administration and continued at a similar rate until the end of the experiment, at least $2 \mathrm{~h}$.

\section{OPTICAL SUPPRESSION OF DRUG-EVOKED DOPAMINE RELEASE}

Approximately $30 \mathrm{~min}$ after drug administration, an optic fiber was used to illuminate the VTA and activate NpHR expressed in dopamine cells. In NpHR-expressing rats, the laser strongly suppressed dopamine release. Figure 3 shows dopamine transient analyses in a representative NpHR-expressing rat. Reduction of dopamine transients was seen robustly from trial to trial (Figure 3B). Interestingly, in an NpHR-expressing rat in which no transients were observed, the laser was still able to reduce dopamine concentration, and revealed the presence of a steadystate level of dopamine, which would not have been detected otherwise (Figure 4).

To analyze the effect of the laser, mean dopamine concentration during the laser epoch was subtracted from mean dopamine concentration during a corresponding baseline epoch that preceded the laser ("laser on" trials; see Section Materials and Methods). This value was compared with a similar calculation performed on trials in which the laser was not turned on ("laser off" trials). Analysis of all NpHR-expressing rats shows a greater suppression of dopamine concentration during "laser on" trials, compared with "laser off" trials (Figure 5A; $t_{(7)}=-3.489$, $p=0.010)$. Control rats were defined as TH-Cre+ rats injected with eYFP reporter or $\mathrm{TH}-\mathrm{Cre}^{-}$rats injected with $\mathrm{NpHR}$. No difference between "laser on" and "laser off" trials was observed in these rats and they were pooled for analysis (Figure 5B; $\left.t_{(4)}=1.569, p=0.192\right)$.

In rats in which dopamine transients were observed, characteristics of transients were further analyzed. One control rat exhibited very low spontaneous activity $(<1$ transient/min) and was excluded from this analysis. In NpHR-expressing rats, the frequency of transients was reduced during "laser on" trials, compared with corresponding "laser off" trials (Figure 6A; $\left.t_{(5)}=-2.961, p=0.031\right)$. This reduction in frequency was not seen in control rats $\left(t_{(3)}=0.397, p=0.718\right)$. Surprisingly, even though transient frequency was reduced during "laser on" trials in NpHR-expressing rats, when transients were detected, their amplitude was not affected by the laser (Figure 6B; $t_{(5)}=-2.014$,
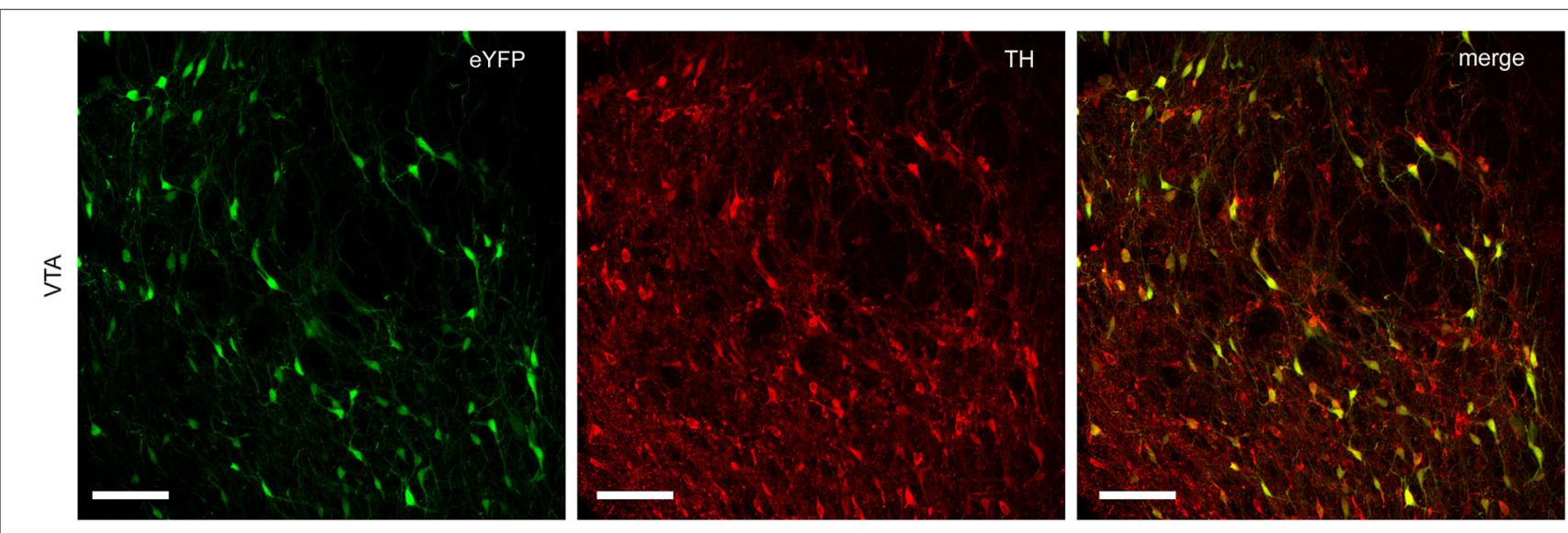

FIGURE 1 | Specific expression of Cre-dependent transgenes in midbrain dopamine neurons. $\mathrm{TH}_{-} \mathrm{Cre}^{+}$rats infected with $\mathrm{Cre}$-dependent eYFP show a high degree of colocalization between eYFP and TH immunoreactivity in VTA. Left-hand panel, eYFP expression (green); center panel, TH immunoreactivity (red); right-hand panel, merged image (yellow). Scale bar $=100 \mu \mathrm{m}$. 

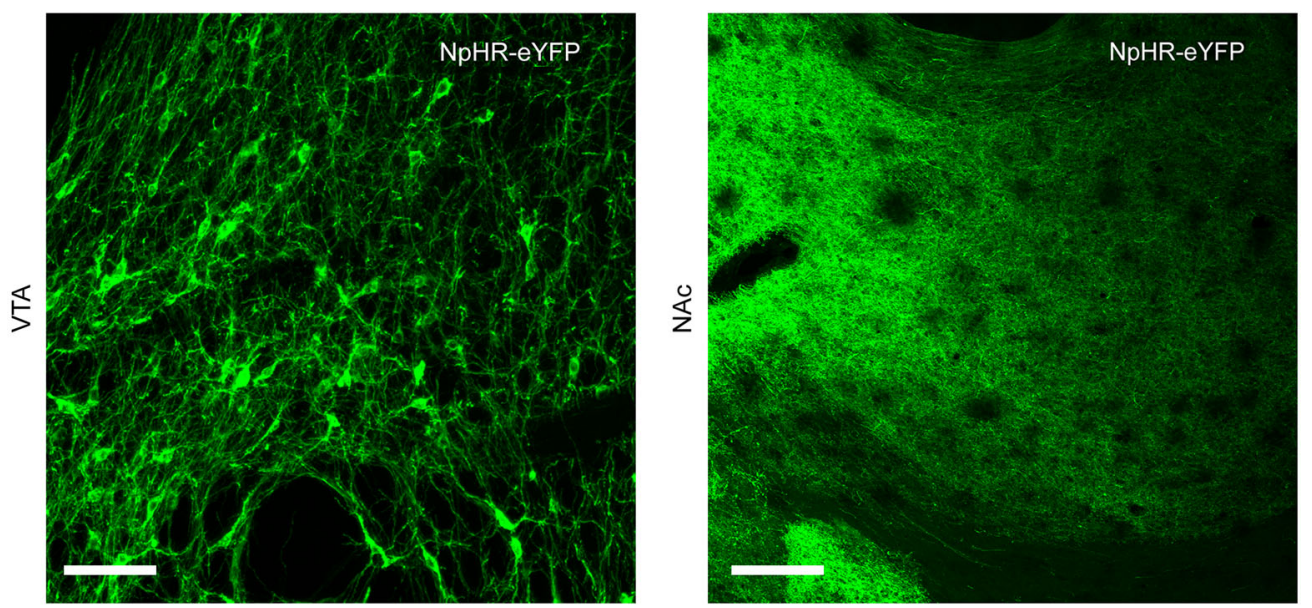

FIGURE 2 | Neurons expressing Cre-dependent transgenes project to NAc. TH-Cre ${ }^{+}$rats infected with Cre-dependent NpHR show expression of eYFP reporter in cell body regions (VTA, left-hand panel) and terminal regions (NAc, right-hand panel). Scale bar $=100 \mu \mathrm{m}$.

A

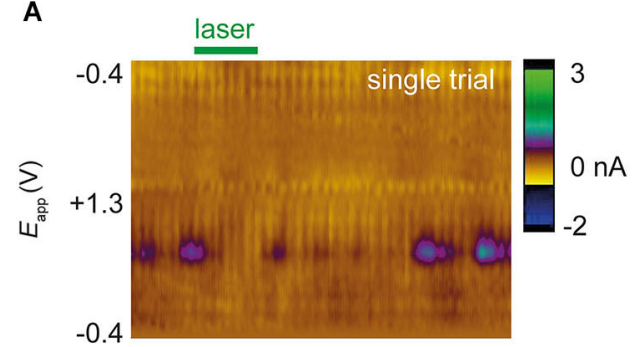

B

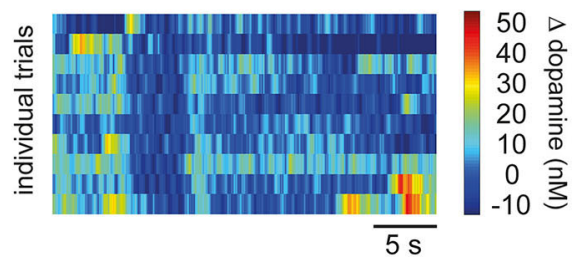

FIGURE 3 | Representative data from a single rat showing optical suppression of drug-evoked dopamine transients. (A) Color plot from single trial after administration of cocaine and raclopride. Applied voltage is on $y$-axis, time is on $x$-axis, and current shown as pseudocolor. Purple features correspond to dopamine oxidation $(\sim+0.6 \mathrm{~V})$. Laser decreases the occurrence

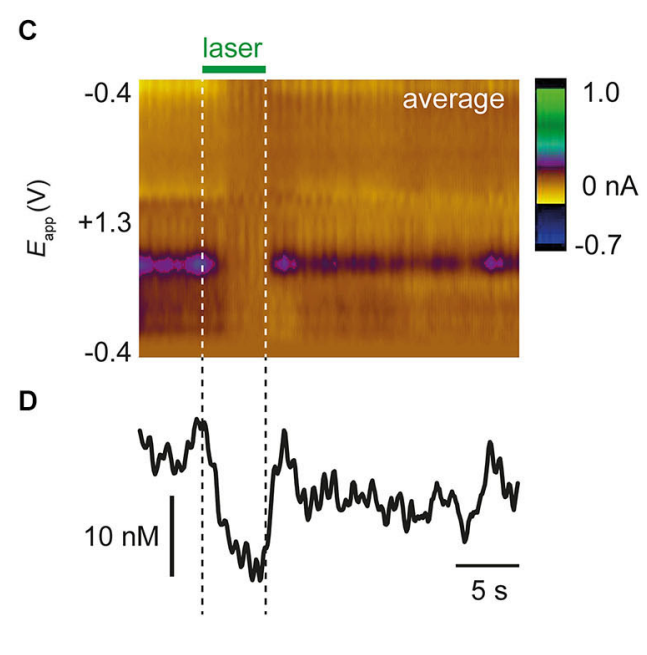

of dopamine transients. (B) 10 individual trials from the same rat showing that the laser consistently reduces occurrence of transients. (C) Average color plot produced from 10 trials in (B). Conventions are the same as in (A).

(D) Dopamine concentration extracted from color plot using principal component analysis. $p=0.100)$. No change in transient amplitude was seen in control rats as a result of laser $\left(t_{(3)}=-0.259, p=0.813\right)$.

\section{DISCUSSION}

Here, we show that somatic hyperpolarization using optogenetics is sufficient to suppress drug-evoked phasic dopamine transients. Specifically, by illuminating dopamine neurons that were selectively transfected with the inhibitory opsin $\mathrm{NpHR}$, we robustly attenuated the occurrence of dopamine transients in NAc produced by co-administration of cocaine and raclopride. We used this pharmacological challenge as it is known to potently drive phasic dopamine release (Venton and Wightman, 2007; Aragona et al., 2008; Park et al., 2010). Fast-scan cyclic voltammetry was used to measure dopamine in vivo due to its sub-second time resolution, which permits detection of brief release events. This study paves the way for future studies using optogenetics to discern the role of dopamine transients in driving drug reinforcement and drug-seeking behaviors.

In this study we recorded from NAc rostral shell. We chose this region as it exhibits a high degree of spontaneous and drugevoked transient activity (Aragona et al., 2008; Roitman et al., 2008; Park et al., 2010; Daberkow et al., 2013). In addition, previous experiments with transgenic $\mathrm{TH}-\mathrm{Cre}^{+}$rats used virus infusion coordinates that targeted medial VTA (Witten et al., 

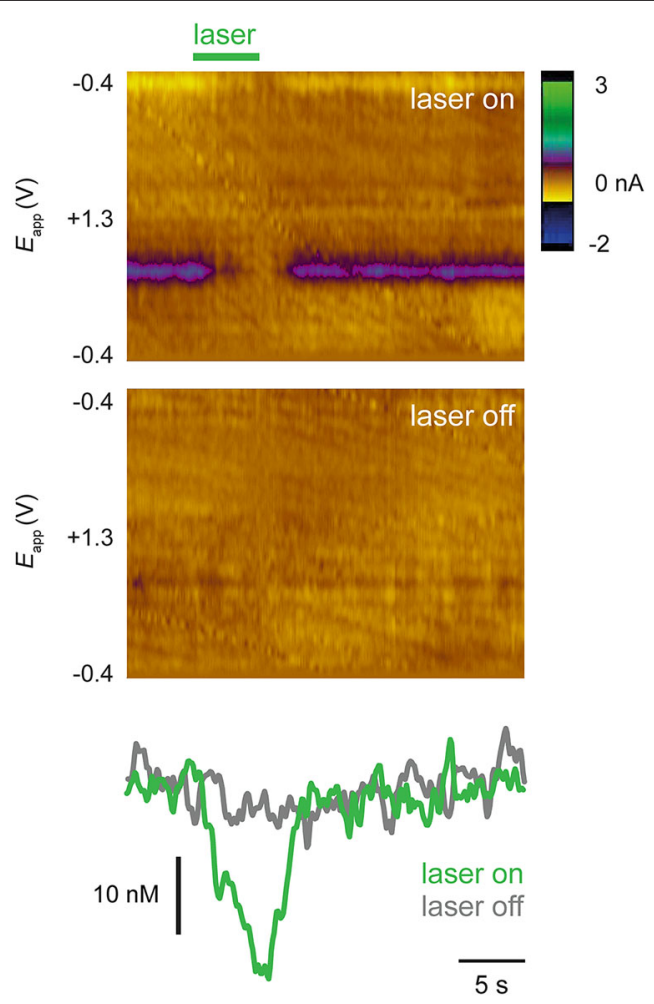

FIGURE 4 | A steady-state pattern of dopamine release is unmasked by optical suppression. Recordings from a rat in which no transients or dopamine release were observed until laser was administered. Top color plot (conventions as in Figure 3A) shows a single trial in which laser was switched on (green bar) and bottom color plot shows single trial in which laser was not switched on. Bottom panels show dopamine concentration traces extracted from color plots. In this rat, steady state dopamine release was not evident until laser was used to activate $\mathrm{NpHR}$.

2011; Steinberg et al., 2013); of the striatal subregions, medial VTA sends densest projections to NAc shell (Ikemoto, 2007). Correspondingly, we found that eYFP expression in terminals was densest, in most rats, in NAc shell. It is unlikely that the efficacy of light to hyperpolarize dopamine neurons and suppress dopamine transients would be different in neurons with different projection targets. Future experiments will confirm if this is indeed the case.

We observed suppression of dopamine release in all NpHRexpressing rats. This finding is consistent with cocaine and raclopride stimulating burst firing in dopamine neurons (Shi et al., 2004) and somatic inhibition suppressing that activity. However, in most cases, we did not block dopamine signaling altogether. That is, while the frequency of transients was reduced during laser epochs transient production was not completely abolished. Indeed, when transients did occur during laser epochs, transient amplitude was not affected. There may be several reasons for this. First, expression of the virus in all dopamine cells was likely not complete due to penetrance of the transgenic strategy, efficiency of the virus, and slight variance in infusion site and virus diffusion. As such, it is possible that the greater degree of suppression seen in some animals was due to a greater opsin expression; in other studies using $\mathrm{TH}-\mathrm{Cre}^{+}$rats, opsin expression has been shown to correlate with behavioral outcome (Witten et al., 2011; Steinberg et al., 2014). Second, the recruitment of infected neurons by light may not have been complete. The VTA is a relatively large area in the rat and light scattering could be problematic. Indeed the degree of light scattering differs depending on brain region (Al-Juboori et al., 2013). Third, it is worth noting that the stimulus we used to evoke dopamine release-co-administration of cocaine and raclopride-is likely to have activated the dopamine system in a supra-physiological manner and this may have prevented optical inhibition of all dopamine release. Indeed, as in this paper we did not directly measure effects on firing we cannot confirm that activation of the NpHR-mediated chloride conductance will completely block spike generation; rather, it may have simply decreased the probability of firing. Finally, and perhaps most intriguing, terminal mechanisms for dopamine release may remain intact even during somatic optical inhibition and act independently of activity in the soma (Exley and Cragg, 2008; Cachope et al., 2012; Threlfell et al., 2012). For example, cocaine increases the activity of NAc cholinergic interneurons (Witten et al., 2010). NAc acetylcholine, in turn, is capable of inducing dopamine release at terminals (Cachope et al., 2012; Threlfell et al., 2012). This last point is especially intriguing in that somatic optical suppression may be a means to determine the relative contributions on somatic vs. terminal influences on NAc dopamine signaling. Thus, it is conceivable that the frequency of transients correlates with somatic burst firing, whereas amplitude of each transient may be more subjected to terminal regulation by dopamine transporters and autoreceptors. Future studies will follow up on this by comparing somatic and terminal activation of opsins.

We observed an increase in dopamine concentration and the probability of a dopamine transient immediately after termination of the laser in some rats, which could be characterized as an inhibition-induced rebound in dopamine concentration. This rebound response could reflect either a property of NpHR (e.g., change in chloride reversal potential after sustained channel opening; Raimondo et al., 2012) or an intrinsic property of dopamine neurons. Consistent with the latter, the response is reminiscent of the brief increase in firing of dopamine cells seen following the termination of an aversive stimulus in some electrophysiology experiments (Brischoux et al., 2009; Wang and Tsien, 2011). The rebound excitation has been suggested to signal relief at termination of an aversive stimulus and could be used by an organism to motivate behavior to learn about aversive events and avoid future occurrences.

Several studies have assessed the contribution of cell body excitability on dopamine transients monitored in dopamine terminal regions. Sombers et al. (2009) used intra-VTA lidocaine or the NMDA receptor antagonist, 2-amino-5-phosphonopentanoic acid, and found near complete suppression of spontaneous and drug-induced dopamine transients. This was replicated with lidocaine in a more recent report (Owesson-White et al., 2012). In contrast, intra-VTA infusion of GABA receptor agonists baclofen and muscimol had no effect on spontaneous transients but blocked the cocaine-evoked increase in transient frequency (Aragona et al., 2008). Although these methods were generally 


\section{A}

NpHR-expressing rats

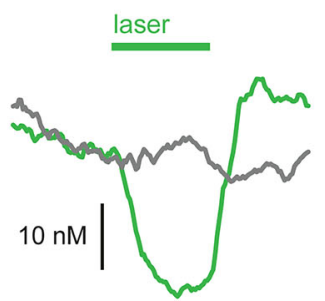

B

control rats

laser

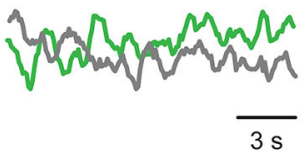

laser on

laser off
C

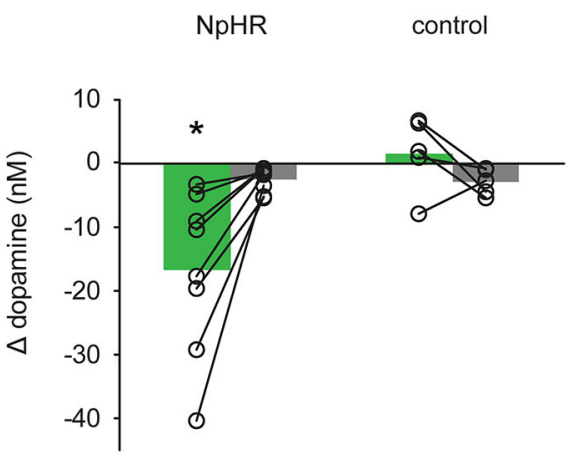

FIGURE 5 | Group data showing optical suppression of dopamine signaling. (A) In TH-Cre ${ }^{+}$rats transfected with $\mathrm{NpHR}(n=8)$, laser illumination of VTA strongly suppressed dopamine, relative to trials in which the laser was not turned on. (B) No effect of laser was seen in control rats $(n=5)$. (C) Quantification of data in (A) and (B). Circles are individual rats and bars are mean values. ${ }^{*} p<0.05$ laser on vs. laser off.
A

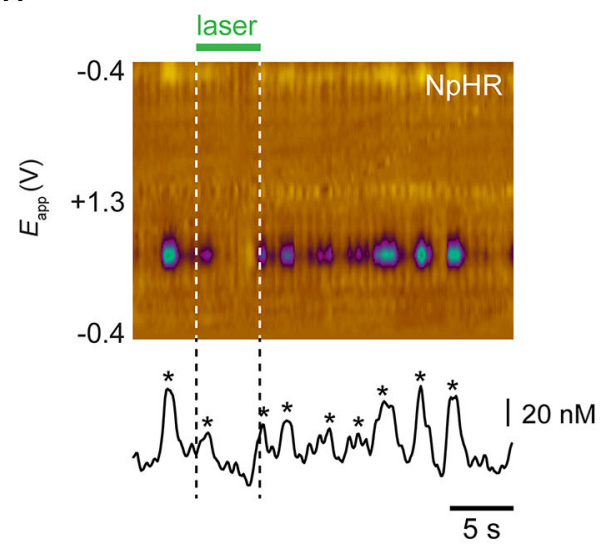

B

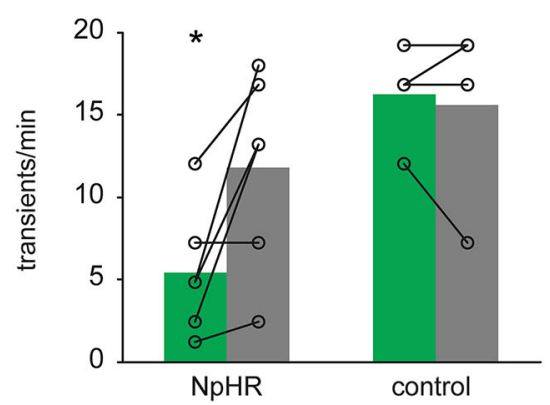

FIGURE 6 | Optical suppression of dopamine transients. (A) Single trial examples showing effect of laser on dopamine transients. Color plots and concentration traces (conventions as in Figure $\mathbf{3 A}$ ) are shown from an NpHR-expressing rat (left-hand panel) and an eYFP-expressing control rat (right-hand panel). Asterices show detected transients. (B) Frequency of

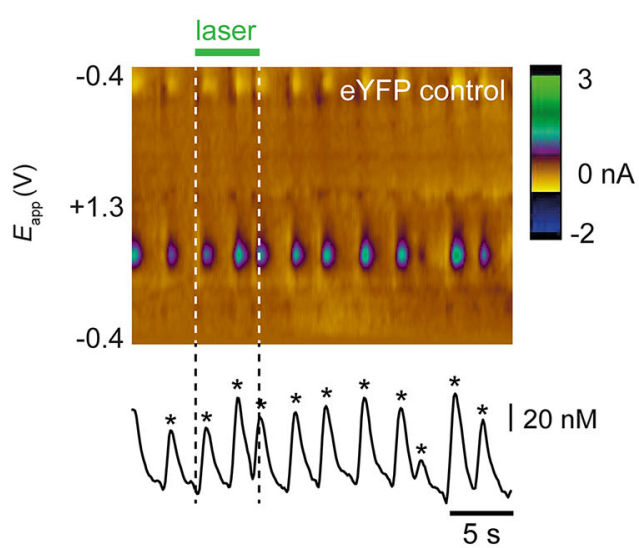

C

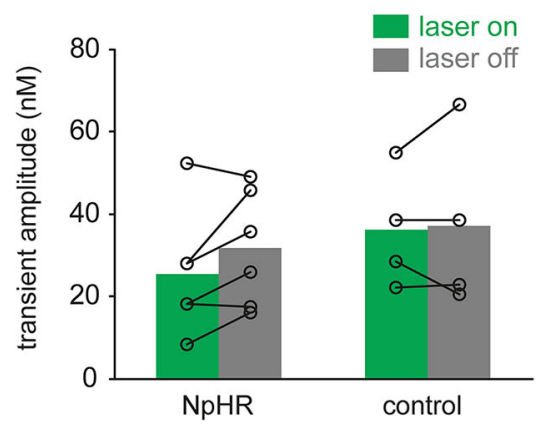

dopamine transients is reduced during laser illumination of VTA, relative to trials in which laser was not turned on, in $\mathrm{TH}^{-C r e}{ }^{+}$rats expressing $\mathrm{NpHR}$ $(n=7)$, but not control rats $(n=4)$. ${ }^{*} p<0.05$ laser on vs. laser off.

(B) Amplitude of transients was not significantly affected by laser illumination in either group. efficient at blocking transients, the use of optogenetics provides an unprecedented degree of both temporal and neuronal population specificity. Thus, optogenetic suppression of drug-induced transients allows the contribution of dopamine neuron excitability to be isolated while leaving GABAergic and other cell types responsive to drug influences. Moreover, it permits the silencing 
of drug-induced transients at brief times that are governed by the experimenter.

A number of studies have used optogenetics to suppress firing of dopamine neurons either by directly targeting dopamine neurons with an inhibitory opsin (Tan et al., 2012; Tye et al., 2013; Danjo et al., 2014; Ilango et al., 2014) or by stimulating GABAergic afferents to dopamine neurons using channelrhodopsin (Stamatakis and Stuber, 2012; Tan et al., 2012; van Zessen et al., 2012; Jennings et al., 2013). In most of these studies, optogenetic suppression of dopamine activity was verified by testing the ability of optical stimulation to suppress action potential firing in vivo or evoke hyperpolarizing currents in dopamine neurons in an ex vivo slice preparation (Tan et al., 2012; van Zessen et al., 2012; Chaudhury et al., 2013; Jennings et al., 2013; Danjo et al., 2014). Two of these studies used fast-scan cyclic voltammetry to examine dopamine release in terminal regions: van Zessen et al. (2012) showed a reduction in electrically-evoked dopamine release caused by activation of GABAergic inputs to dopamine cells and Danjo et al. (2014) showed a reduction in electrically-evoked dopamine release and tonic levels of dopamine caused by activation of the inhibitory opsin, ArchT, in dopamine neurons. Our work significantly extends these findings to optical suppression of drug-induced dopamine concentration transients. While our work was conducted in anesthetized rats, the drug cocktail (cocaine and raclopride) delivered has been shown to robustly stimulate dopamine concentration transients in both anesthetized (Park et al., 2010) and awake, behaving rats (Aragona et al., 2008). Future work will address whether optical suppression of drug-evoked dopamine concentration transients is sufficient to prevent the development of drug-directed behavior. Interestingly, a different approach to dopamine neuron activity modulation using a designer receptor exclusively activated by designer drug (DREADD) has been shown to affect reinstatement for drug seeking (Mahler et al., 2014).

Optogenetic inhibition of dopamine cells increased immobility in the tail suspension test and reduced sucrose preference (Tye et al., 2013), or induced a real-time and conditioned place avoidance (Tan et al., 2012; Danjo et al., 2014; Ilango et al., 2014). Indirect suppression of dopamine neurons via GABAergic afferents disrupts reward consumption (van Zessen et al., 2012), induces real-time place avoidance, and marks the onset of anxiety-like behavior in an open field (Stamatakis and Stuber, 2012; Jennings et al., 2013). Thus, optogenetic disruption of dopamine cell activity during behavior results in robust behavioral outcomes, many of which resemble an aversive state (although see Chaudhury et al., 2013). That optical suppression of dopamine release induces indices of depression and aversion matches well with real-time recordings made of NAc dopamine concentration in response to aversive stimuli (Roitman et al., 2008; Wheeler et al., 2011; McCutcheon et al., 2012).

In summary, somatic hyperpolarization of dopamine neurons is sufficient to suppress the occurrence of dopamine transients in terminal regions. As de novo generation of dopamine transients is a key feature common to all abused drugs (Covey et al., 2014), that optical somatic inhibition can suppress drug-induced dopamine transients offers new opportunities to control drug reinforcement and drug-seeking behaviors. Future studies will use optogenetics to determine the precise contribution of drug-evoked transients to drug-associated behaviors.

\section{ACKNOWLEDGMENTS}

The following sources of funding contributed to this work: NIH K01 grant 033380 (James E. McCutcheon), NIH R01 025634 (Mitchell F. Roitman), Fay/Feed Seed Grant from the Brain Research Foundation (Mitchell F. Roitman). We thank Dr. E. Steinberg for helpful advice on making infusions.

\section{REFERENCES}

Al-Juboori, S. I., Dondzillo, A., Stubblefield, E. A., Felsen, G., Lei, T. C., and Klug, A. (2013). Light scattering properties vary across different regions of the adult mouse brain. PLoS One 8:e67626. doi: 10.1371/journal.pone.0067626

Aragona, B. J., Cleaveland, N. A., Stuber, G. D., Day, J. J., Carelli, R. M., and Wightman, R. M. (2008). Preferential enhancement of dopamine transmission within the nucleus accumbens shell by cocaine is attributable to a direct increase in phasic dopamine release events. J. Neurosci. 28, 8821-8831. doi: 10. 1523/jneurosci.2225-08.2008

Brischoux, F., Chakraborty, S., Brierley, D. I., and Ungless, M. A. (2009). Phasic excitation of dopamine neurons in ventral VTA by noxious stimuli. Proc. Natl. Acad. Sci. U S A 106, 4894-4899. doi: 10.1073/pnas.0811507106

Brodie, M. S., Pesold, C., and Appel, S. B. (1999). Ethanol directly excites dopaminergic ventral tegmental area reward neurons. Alcohol. Clin. Exp. Res. 23, 1848 1852. doi: 10.1111/j.1530-0277.1999.tb04082.x

Cachope, R., Mateo, Y., Mathur, B. N., Irving, J., Wang, H.-L., Morales, M., et al. (2012). Selective activation of cholinergic interneurons enhances accumbal phasic dopamine release: setting the tone for reward processing. Cell Rep. 2, 33 41. doi: 10.1016/j.celrep.2012.05.011

Chaudhury, D., Walsh, J. J., Friedman, A. K., Juarez, B., Ku, S. M., Koo, J. W., et al. (2013). Rapid regulation of depression-related behaviours by control of midbrain dopamine neurons. Nature 493, 532-536. doi: 10.1038/nature 11713

Cheer, J. F., Wassum, K. M., Heien, M. L. A. V., Phillips, P. E. M., and Wightman, R. M. (2004). Cannabinoids enhance subsecond dopamine release in the nucleus accumbens of awake rats. J. Neurosci. 24, 4393-4400. doi: 10.1523/jneurosci. 0529-04.2004

Cheer, J. F., Wassum, K. M., Sombers, L. A., Heien, M. L. A. V., Ariansen, J. L., Aragona, B. J., et al. (2007). Phasic dopamine release evoked by abused substances requires cannabinoid receptor activation. J. Neurosci. 27, 791-795. doi: 10.1523/jneurosci.4152-06.2007

Cone, J. J., Chartoff, E. H., Potter, D. N., Ebner, S. R., and Roitman, M. F. (2013). Prolonged high fat diet reduces dopamine reuptake without altering DAT gene expression. PLoS One 8:e58251. doi: 10.1371/journal.pone.0058251

Covey, D. P., Roitman, M. F., and Garris, P. A. (2014). Illicit dopamine transients: reconciling actions of abused drugs. Trends Neurosci. 37, 200-210. doi: 10.1016/j. tins.2014.02.002

Daberkow, D. P., Brown, H. D., Bunner, K. D., Kraniotis, S. A., Doellman, M. A., Ragozzino, M. E., et al. (2013). Amphetamine paradoxically augments exocytotic dopamine release and phasic dopamine signals. J. Neurosci. 33, 452-463. doi: 10.1523/JNEUROSCI.2136-12.2013

Danjo, T., Yoshimi, K., Funabiki, K., Yawata, S., and Nakanishi, S. (2014). Aversive behavior induced by optogenetic inactivation of ventral tegmental area dopamine neurons is mediated by dopamine D2 receptors in the nucleus accumbens. Proc. Natl. Acad. Sci. U S A 111, 1-6. doi: 10.1073/pnas.140432 3111

Day, J. J., Roitman, M. F., Wightman, R. M., and Carelli, R. M. (2007). Associative learning mediates dynamic shifts in dopamine signaling in the nucleus accumbens. Nat. Neurosci. 10, 1020-1028. doi: 10.1038/nn1923

Exley, R., and Cragg, S. J. (2008). Presynaptic nicotinic receptors: a dynamic and diverse cholinergic filter of striatal dopamine neurotransmission. Br. J. Pharmacol. 153(Suppl. 1), S283-S297. doi: 10.1038/sj.bjp.0707510

Gessa, G. L., Melis, M., Muntoni, A. L., and Diana, M. (1998). Cannabinoids activate mesolimbic dopamine neurons by an action on cannabinoid CB1 receptors. Eur. J. Pharmacol. 341, 39-44. doi: 10.1016/s0014-2999(97)01442-8

Gysling, K., and Wang, R. Y. (1983). Morphine-induced activation of A10 dopamine neurons in the rat. Brain Res. 277, 119-127. doi: 10.1016/0006-8993(83)90913-7 
Heien, M. L. A. V., Johnson, M. A., and Wightman, R. M. (2004). Resolving neurotransmitters detected by fast-scan cyclic voltammetry. Anal. Chem. 76, 5697-5704. doi: 10.1021/ac0491509

Ikemoto, S. (2007). Dopamine reward circuitry: two projection systems from the ventral midbrain to the nucleus accumbens-olfactory tubercle complex. Brain Res. Rev. 56, 27-78. doi: 10.1016/j.brainresrev.2007.05.004

Ilango, A., Kesner, A. J., Keller, K. L., Stuber, G. D., Bonci, A., and Ikemoto, S. (2014). Similar roles of substantia nigra and ventral tegmental dopamine neurons in reward and aversion. J. Neurosci. 34, 817-822. doi: 10.1523/jneurosci. 1703-13.2014

Jennings, J. H., Sparta, D. R., Stamatakis, A. M., Ung, R. L., Pleil, K. E., Kash, T. L., et al. (2013). Distinct extended amygdala circuits for divergent motivational states. Nature 496, 224-228. doi: 10.1038/nature12041

Keithley, R. B., Carelli, R. M., and Wightman, R. M. (2010). Rank estimation and the multivariate analysis of in vivo fast-scan cyclic voltammetric data. Anal. Chem. 82, 5541-5551. doi: 10.1021/ac100413t

Koulchitsky, S., De Backer, B., Quertemont, E., Charlier, C., and Seutin, V. (2012). Differential effects of cocaine on dopamine neuron firing in awake and anesthetized rats. Neuropsychopharmacology 37, 1559-1571. doi: 10.1038/npp.20 11.339

Lüscher, C., and Ungless, M. A. (2006). The mechanistic classification of addictive drugs. PLoS Med. 3:e437. doi: 10.1371/journal.pmed.0030437

Mahler, S. V., Vazey, E. M., Beckley, J. T., Keistler, C. R., McGlinchey, E. M., Kaufling, J., et al. (2014). Designer receptors show role for ventral pallidum input to ventral tegmental area in cocaine seeking. Nat. Neurosci. 17, 577-585. doi: 10.1038/nn.3664

McCutcheon, J. E., Conrad, K. L., Carr, S. B., Ford, K. A., McGehee, D. S., and Marinelli, M. (2012). Dopamine neurons in the ventral tegmental area fire faster in adolescent rats than in adults. J. Neurophysiol. 108, 1620-1630. doi: 10. 1152/jn.00077.2012

McCutcheon, J. E., Ebner, S. R., Loriaux, A. L., and Roitman, M. F. (2012). Encoding of aversion by dopamine and the nucleus accumbens. Front. Neurosci. 6:137. doi: 10.3389/fnins.2012.00137

Mereu, G., Yoon, K. W., Boi, V., Gessa, G. L., Naes, L., and Westfall, T. C. (1987). Preferential stimulation of ventral tegmental area dopaminergic neurons by nicotine. Eur. J. Pharmacol. 141, 395-399. doi: 10.1016/0014-2999(87)90556-5

Owesson-White, C. A., Roitman, M. F., Sombers, L. A., Belle, A. M., Keithley, R. B., Peele, J. L., et al. (2012). Sources contributing to the average extracellular concentration of dopamine in the nucleus accumbens. J. Neurochem. 121, 252262. doi: 10.1111/j.1471-4159.2012.07677.x

Park, J., Aragona, B. J., Kile, B. M., Carelli, R. M., and Wightman, R. M. (2010). In vivo voltammetric monitoring of catecholamine release in subterritories of the nucleus accumbens shell. Neuroscience 169, 132-142. doi: 10.1016/j. neuroscience.2010.04.076

Phillips, P. E. M., Stuber, G. D., Heien, M. L. A. V., Wightman, R. M., and Carelli, R. M. (2003). Subsecond dopamine release promotes cocaine seeking. Nature 422, 614-618. doi: 10.1038/nature01476

Raimondo, J. V., Kay, L., Ellender, T. J., and Akerman, C. J. (2012). Optogenetic silencing strategies differ in their effects on inhibitory synaptic transmission. Nat. Neurosci. 15, 1102-1104. doi: 10.1038/nn.3143

Robinson, D. L., Howard, E. C., McConnell, S., Gonzales, R. A., and Wightman, R. M. (2009). Disparity between tonic and phasic ethanol-induced dopamine increases in the nucleus accumbens of rats. Alcohol. Clin. Exp. Res. 33, 11871196. doi: 10.1111/j.1530-0277.2009.00942.x

Roitman, M. F., Wheeler, R. A., Wightman, R. M., and Carelli, R. M. (2008). Realtime chemical responses in the nucleus accumbens differentiate rewarding and aversive stimuli. Nat. Neurosci. 11, 1376-1377. doi: 10.1038/nn.2219

Shi, W.-X. X., Pun, C.-L., and Zhou, Y. (2004). Psychostimulants induce lowfrequency oscillations in the firing activity of dopamine neurons. Neuropsychopharmacology 29, 2160-2167. doi: 10.1038/sj.npp.1300534

Sinkala, E., McCutcheon, J. E., Schuck, M. J., Schmidt, E., Roitman, M. F., and Eddington, D. T. (2012). Electrode calibration with a microfluidic flow cell for fast-scan cyclic voltammetry. Lab Chip 12, 2403-2408. doi: 10.1039/c2lc4 $0168 \mathrm{a}$

Sombers, L. A., Beyene, M., Carelli, R. M., and Wightman, R. M. (2009). Synaptic overflow of dopamine in the nucleus accumbens arises from neuronal activity in the ventral tegmental area. J. Neurosci. 29, 1735-17342. doi: 10.1523/jneurosci. 5562-08.2009
Sparta, D. R., Stamatakis, A. M., Phillips, J. L., Hovelsø, N., van Zessen, R., and Stuber, G. D. (2012). Construction of implantable optical fibers for long-term optogenetic manipulation of neural circuits. Nat. Protoc. 7, 12-23. doi: 10. 1038/nprot.2011.413

Stamatakis, A. M., and Stuber, G. D. (2012). Activation of lateral habenula inputs to the ventral midbrain promotes behavioral avoidance. Nat. Neurosci. 15, 11051107. doi: $10.1038 / \mathrm{nn} .3145$

Steinberg, E. E., Boivin, J. R., Saunders, B. T., Witten, I. B., Deisseroth, K., and Janak, P. H. (2014). Positive reinforcement mediated by midbrain dopamine neurons requires $\mathrm{d} 1$ and $\mathrm{d} 2$ receptor activation in the nucleus accumbens. PLoS One 9:e94771. doi: 10.1371/journal.pone.0094771

Steinberg, E. E., Keiflin, R., Boivin, J. R., Witten, I. B., Deisseroth, K., and Janak, P. H. (2013). A causal link between prediction errors, dopamine neurons and learning. Nat. Neurosci. 16, 966-973. doi: 10.1038/nn.3413

Tan, K. R., Yvon, C., Turiault, M., Mirzabekov, J. J., Doehner, J., Labouèbe, G., et al. (2012). GABA neurons of the VTA drive conditioned place aversion. Neuron 73, 1173-1183. doi: 10.1016/j.neuron.2012.02.015

Threlfell, S., Lalic, T., Platt, N. J., Jennings, K. A., Deisseroth, K., and Cragg, S. J. (2012). Striatal dopamine release is triggered by synchronized activity in cholinergic interneurons. Neuron 75, 58-64. doi: 10.1016/j.neuron.2012.04.038

Tsai, H.-C., Zhang, F., Adamantidis, A., Stuber, G. D., Bonci, A., de Lecea, L., et al. (2009). Phasic firing in dopaminergic neurons is sufficient for behavioral conditioning. Science 324, 1080-1084. doi: 10.1126/science.1168878

Tye, K. M., Mirzabekov, J. J., Warden, M. R., Ferenczi, E. A., Tsai, H.-C., Finkelstein, J., et al. (2013). Dopamine neurons modulate neural encoding and expression of depression-related behaviour. Nature 493, 537-541. doi: 10.1038/nature11740

van Zessen, R., Phillips, J. L., Budygin, E. A., and Stuber, G. D. (2012). Activation of VTA GABA neurons disrupts reward consumption. Neuron 73, 1184-1194. doi: 10.1016/j.neuron.2012.02.016

Venton, B. J., and Wightman, R. M. (2007). Pharmacologically induced, subsecond dopamine transients in the caudate-putamen of the anesthetized rat. Synapse 61, 37-39. doi: 10.1002/syn.20343

Wang, D. V., and Tsien, J. Z. (2011). Convergent processing of both positive and negative motivational signals by the VTA dopamine neuronal populations. PLoS One 6:e17047. doi: 10.1371/journal.pone.0017047

Wheeler, R. A., Aragona, B. J., Fuhrmann, K. A., Jones, J. L., Day, J. J., Cacciapaglia, F., et al. (2011). Cocaine cues drive opposing context-dependent shifts in reward processing and emotional state. Biol. Psychiatry 69, 1067-1074. doi: 10.1016/j. biopsych.2011.02.014

Willuhn, I., Burgeno, L. M., Everitt, B. J., and Phillips, P. E. M. (2012). Hierarchical recruitment of phasic dopamine signaling in the striatum during the progression of cocaine use. Proc. Natl. Acad. Sci. U S A 109, 20703-20708. doi: 10. 1073/pnas. 1213460109

Witten, I. B., Lin, S.-C., Brodsky, M., Prakash, R., Diester, I., Anikeeva, P., et al. (2010). Cholinergic interneurons control local circuit activity and cocaine conditioning. Science 330, 1677-1681. doi: 10.1126/science.1193771

Witten, I. B., Steinberg, E. E., Lee, S. Y., Davidson, T. J., Zalocusky, K. A., Brodsky, M., et al. (2011). Recombinase-driver rat lines: tools, techniques and optogenetic application to dopamine-mediated reinforcement. Neuron 72, 721-733. doi: 10 . 1016/j.neuron.2011.10.028

Conflict of Interest Statement: The authors declare that the research was conducted in the absence of any commercial or financial relationships that could be construed as a potential conflict of interest.

Received: 22 May 2014; accepted: 31 August 2014; published online: 17 September 2014.

Citation: McCutcheon JE, Cone JJ, Sinon CG, Fortin SM, Kantak PA, Witten IB, Deisseroth K, Stuber GD and Roitman MF (2014) Optical suppression of drug-evoked phasic dopamine release. Front. Neural Circuits 8:114. doi: 10.3389/fncir.2014.00114 This article was submitted to the journal Frontiers in Neural Circuits.

Copyright (C) 2014 McCutcheon, Cone, Sinon, Fortin, Kantak, Witten, Deisseroth, Stuber and Roitman. This is an open-access article distributed under the terms of the Creative Commons Attribution License (CC BY). The use, distribution or reproduction in other forums is permitted, provided the original author(s) or licensor are credited and that the original publication in this journal is cited, in accordance with accepted academic practice. No use, distribution or reproduction is permitted which does not comply with these terms. 